\title{
Rural-urban disparities in maternal immunization knowledge and childhood health- seeking behavior in Nigeria: a mixed method study
}

\author{
Ifeoma P Okafor ${ }^{1}$, Duro C Dolapo ${ }^{2}$, Modupe O Onigbogi ${ }^{3}$, Iruoma G Iloabuchi ${ }^{3}$
}

\begin{abstract}
1.Department of Community Health \& Primary Care, College of Medicine, Idi-Araba, P.M.B. 12003, Lagos, Nigeria 2.Leverage Consulting Ltd, Road 425, Zone 6, Abuja, Nigeria

3.Department of Community Health \& Primary Care, Lagos University Teaching Hospital, Idi-Araba, P.M.B. 12003, Lagos, Nigeria
\end{abstract}

\begin{abstract}
Background: Immunization and appropriate health-seeking behavior are effective strategies to reduce child deaths. Objectives: To compare maternal knowledge about immunization, use of growth chart and childhood health-seeking behavior in rural and urban areas.

Methods: A cross-sectional comparative study done in Lagos, Nigeria. Questionnaire survey and focus group discussions were done. 300 respondents were selected by multi-stage sampling while discussants were purposively selected.

Results:

Awareness of immunization was high but knowledge of vaccine preventable diseases (VPDs) was poor in both areas. Urban women utilized preventive services more; growth monitoring $(p<0.001)$ and immunization $(p<0.001)$ while higher proportions of rural women utilized nutritional counseling $(\mathrm{p}=0.005)$ and treatment of illness $(\mathrm{p}<0.001)$. Growth chart utilization was better in the urban areas $(\mathrm{p}<0.001)$. Increasing maternal education increased use of growth chart in both areas. Both groups of women use multiple treatment sources for children (more in urban), determined by cost, time, perceived severity of illness and type of ailment (urban) and peculiarity of illness (rural). There is a preference for orthodox care in the rural area.

\section{Conclusions:}

Knowledge of VPDs was poor and multiple treatment sources were common among rural and urban women. Education is vital to improve immunization knowledge and health-seeking behavior in both areas.
\end{abstract}

Key Words: Immunization; growth chart; health-seeking behavior; child health; Nigeria

African Health Sciences 2014; 14(2):339-347

DOI: http://dx.doi.org/10.4314/ahs.v14i2.8

\section{Introduction}

Immunization is one of the most essential public health interventions and cost effective strategy to reduce childhood morbidity and mortality. It is estimated to prevent between 2 and 3 million deaths each year. ${ }^{1}$ The Expanded Program on Immunization (EPI) in Nigeria was introduced in 1979 to ensure universal access to

\section{Corresponding Author: \\ Dr Ifeoma P Okafor \\ Department of Community Health \& Primary Care, College of Medicine, University of Lagos, Idi-Araba, PMB 12003, Lagos, Nigeria. \\ Phone numbers: 234-8033272199, 234-7043294609 \\ e-mail : iphomaa@yahoo.com}

recommended childhood vaccines but was later restructured with a view to improve the effectiveness of immunization coverage and increase the number of antigens. The Vaccine Preventable diseases (VPDs) covered in the immunization schedule presently in Nigeria for children aged 0-1 year include Tuberculosis, Poliomyelitis, Diphtheria, Pertussis, Tetanus, Hepatitis B, Hemophilus influenza B virus infections, Measles and Yellow Fever. ${ }^{2}$

Globally in 2010, approximately $50 \%$ of the 19.3 million infants who were not fully vaccinated lived in India, Nigeria and the Democratic Republic of Congo (DRC). ${ }^{3}$ Immunization coverage in Nigeria has remained low despite introduction of supplemental immunization programs and various strategies in a bid to achieve MDG $4 .{ }^{4}$ Nigeria still has one of the highest under five mortality rates of 157 per 1000; the proportion of fully vaccinated children aged 12-23 months only increased from $13 \%$ in 2003 to $23 \%$ in 2008 (NDHS 2008). ${ }^{5}$ The uptake of immunization services is dependent not only 
on provision of these services but also on other factors including knowledge and attitude of mothers, ${ }^{6-8}$ density of health workers ${ }^{9}$ and accessibility to vaccination clinics and availability of safe needles and syringes. In the rural area, other factors responsible for incomplete immunizations include parents' objection, disagreement or concern about immunization safety, long walking distance and long waiting time at the health facility. ${ }^{10}$ In a predominantly rural part of Ghana, traders and hairdressers had the least knowledge about all vaccines. Immunization knowledge was significantly related to age, occupation, educational status and socioeconomic status of the mothers. ${ }^{11}$

Growth charts are important tools for monitoring child growth. A review of literature showed that parents and caregivers lack knowledge and understanding of growth charts and this may limit their benefits as educational tools by healthcare providers. ${ }^{12}$ Unfortunately, in both rural and urban areas, there is low usage of growth charts in health facilities. ${ }^{13,14}$

Delay in seeking appropriate healthcare for sick children can potentially result in mortality especially in developing countries. ${ }^{15} \mathrm{It}$ is estimated that one-fifths of child deaths due to acute respiratory infections could be prevented by seeking prompt and appropriate care. ${ }^{16}$ Factors such as child gender, maternal education and income, household size, number of symptoms and severity of illness may influence care-seeking for children generally. ${ }^{17-19}$ Multiple sources of healthcare for a sick child are common among both urban and rural caregivers. Even when public health services are provided free, many women still utilize other sources of treatment and eventually lose their infants in the process. ${ }^{20}$ In India, factors such as low maternal autonomy negatively influence maternal use of preventive and curative healthcare for their children. ${ }^{21}$

Community case management (CCM) of common childhood illnesses using trained and supervised community health workers has been shown to improve access to treatment, quality of care and caregiver demand and is a worthy strategy to ensure equity in healthcare access and achieving MDG 4. ${ }^{22,23}$

The study aimed to determine rural-urban differences in mothers' knowledge about immunization, and their use of growth chart and child health services. It also set out to ascertain pathways for treatment-seeking for childhood illnesses in the two areas.

\section{Design and methods}

Lagos State is a megacity with a population density of over 1,000 persons per square kilometer. It has 20 Local Government Areas (LGAs), 4 of which are rural and 16, urban. This stratification is based on the availability of social amenities and infrastructure such as pipe borne water, electricity and good road networks. Surulere LGA (with about 1.3 million inhabitants) was selected from the urban LGAs. Ibeju-Lekki (with about 100,000 inhabitants) was selected from the rural LGAs. Both LGAs have PHCs, secondary health facilities and numerous private health facilities. None of the LGAs has tertiary health institution. TBAs and alternative healthcare providers operate in both LGAs.

The design of the study was cross-sectional and comparative carried out in 2010. The study population was women of child-bearing age (15-45 years) who were resident in the area. Only women with underfive children were included in the study and they were questioned on the youngest child. A minimum sample size of about 277 per group was derived using the formula for comparing independent groups at a power of $80 \%$, critical value at $5 \%$ significance (1.96), P1 20\% and P2 $11.9 \% .{ }^{24,25}$ This was increased to 300 ie total of 600. A multi-stage sampling technique was employed in the selection of respondents. At each stage, simple random sampling was used in selection.

Five wards were selected in each LGA. In each ward, a street was selected initially and the starting point (house) was randomly selected. One eligible respondent was then interviewed in consecutive houses starting from the selected house. More streets were chosen and the process continued until desired sample size was achieved. An equally proportionate number of respondents were interviewed in each ward.

Quantitative data were collected with a structured, interviewer-administered questionnaire which was pretested on 20 respondents. Data was analyzed with epiinfo V3.5.1and winpepi statistical software. Inferential statistics was done with chi square test, fisher's exact test, odds ratio and confidence interval with a significant level of $5 \%$.

Three FGDs were conducted in each of the LGAs using a semi-structured, pre-tested interview guide and was audio-taped. Discussants were purposively recruited. Applying the framework analysis method, transcripts were first read for a general overview, clarity and comprehension. Author's notes from the field supplemented the text. This stage was followed by familiarization with the data, achieved by listening to tapes, reading the transcripts and observational notes taken during interview. The next stage involved identifying a thematic framework- themes were developed both from the research questions and from the narratives of research participants. Descriptive 
statements were formed and an analysis was carried out on the data under the questioning route. This was followed by indexing, highlighting and sorting out quotes and making comparisons both within and between cases. Quotes were then lifted from their original context and re-arranged under the newly-developed appropriate thematic content and then finally, mapped and interpreted.

\section{Results}

\section{Socio-demography}

The highest proportion of women was between 26-30 years, $102(34.0 \%)$ for the rural area $94(31.3 \%)$ and for the urban area. The mean age was 30.9 $\pm 5.9 y e a r s$ in the rural area and $31.4 \pm 6.1$ years in the urban area.

Majority, $212(70.7 \%)$ of the women in the rural and the urban area, $258(86.0 \%)$ were married. The mean number of children for the rural women was $3.1 \pm 1.5$ and $2.6 \pm 1.1$ for the urban women. The rural women significantly had more children than the urban women. More than half, 175 (58.3\%) of the urban women had secondary school education and only 13(4.3\%) did not have any formal education. For the rural women, less than half, 145 (48.3\%) had secondary school education and $24(8.0 \%)$ had no formal education. The urban women were significantly better educated.

Sixty five $(21.7 \%)$ of the rural women were unemployed, while $76(32.0 \%)$ of the urban women were unemployed. Of all the respondents, only one urban woman was a professional.

\section{Awareness of VPDs and growth chart}

Awareness of immunization was high $(100 \%)$ in both areas. The VPD known to most rural (78.67\%) and urban $(83.3 \%)$ women was poliomyelitis, followed by measles $(75.7 \%)$, rural and $(71.7 \%)$ urban.

Awareness of growth monitoring was significantly better in the urban area $(p=0.035)$. Almost equal proportions of rural and urban women knew about the growth chart with no significant difference $(\mathrm{p}=0.794)$. (Table 1$)$

Table 1: Respondents' awareness of immunization, vaccine preventable diseases, growth monitoring and growth chart

\begin{tabular}{lllll}
\hline Variable & $\begin{array}{c}\text { Rural } \\
\text { Frequency(\%) }\end{array}$ & $\begin{array}{c}\text { Urban } \\
\text { Frequency }(\%)\end{array}$ & $\chi^{2}$ & p \\
\hline VPDs known & & & & \\
Tuberculosis & $85(28.3)$ & $156(52.0)$ & 34.96 & $<0.001^{*}$ \\
Diphtheria & $47(15.7)$ & $54(18.0)$ & 0.58 & 0.445 \\
Whooping cough & $120(40.0)$ & $100(33.3)$ & 2.87 & 0.090 \\
Tetanus & $100(33.3)$ & $86(28.7)$ & 1.53 & 0.217 \\
Measles & $227(75.7)$ & $215(71.7)$ & 1.24 & 0.266 \\
Yellow fever & $141(47.0)$ & $135(45.0)$ & 0.24 & 0.623 \\
Hepatitis B & $84(28.0)$ & $68(22.7)$ & 2.26 & 0.133 \\
Meningitis & $52(17.3)$ & $22(7.3)$ & 13.87 & $<0.001^{*}$ \\
Poliomyelitis & $236(78.7)$ & $250(83.3)$ & 2.12 & 0.145 \\
Others & $7(2.3)$ & $9(3.0)$ & 0.26 & 0.612 \\
\hline Aware of growth & & & & \\
monitoring & & & & \\
Yes & $207(69.0)$ & $230(76.7)$ & 4.46 & $0.035^{*}$ \\
No & $93(31.0)$ & $70(23.3)$ & & \\
Total & $300(100)$ & $300(100)$ & & \\
\hline Aware of growth chart & \multicolumn{2}{c}{0.07} & 0.794 \\
Yes & $203(67.7)$ & $200(66.7)$ & & \\
No & $97(32.3)$ & $100(33.3)$ & & \\
Total & $300(100)$ & $300(100)$ & & \\
\hline
\end{tabular}

*Significant

\section{Utilization of child healthcare services}

A significantly higher proportion of urban women utilized the health facilities for growth monitoring and immunization while rural women utilized the health facilities more for treatment of illness and nutritional counseling for their children. Less than one-third $(30.2 \%)$ of the rural women and less than half $(48.1 \%)$ of the urban women utilized growth charts with significant differences. (Table 2) 
Table 2: Respondents' use of child health services

\begin{tabular}{|c|c|c|c|c|}
\hline (1) & $\begin{array}{l}\text { Rural } \\
\text { Freq(\%) }\end{array}$ & $\begin{array}{l}\text { Urban } \\
\text { Freg( } \%)\end{array}$ & $\chi^{2}$ & $\mathrm{p}$ \\
\hline $\begin{array}{l}\text { Has ever taken child to health facility } \\
\text { (after a live birth) } \\
\text { Yes } \\
\text { No }\end{array}$ & $\begin{array}{l}258(93.5) \\
18(6.5)\end{array}$ & $\begin{array}{l}289(96.7) \\
1(3.3)\end{array}$ & 3.13 & 0.077 \\
\hline $\begin{array}{l}\text { Reasons for clinic visits } \\
\text { Growth monitoring } \\
\text { Immunization } \\
\text { Treatment of illness } \\
\text { Nutritional counseling } \\
\text { Others }\end{array}$ & $\begin{array}{l}126(48.8) \\
212(82.2) \\
91(35.3) \\
42(16.3) \\
11(4.3) \\
\text { Multiple responses }\end{array}$ & $\begin{array}{l}221(76.5) \\
260(90.0) \\
40(13.8) \\
21(7.3) \\
7(2.4)\end{array}$ & $\begin{array}{l}61.68 \\
22.88 \\
25.40 \\
7.82 \\
0.92\end{array}$ & $\begin{array}{l}0.000^{*} \\
0.000^{*} \\
0.000^{*} \\
0.005^{*} \\
0.338\end{array}$ \\
\hline $\begin{array}{l}\text { Use of growth chart } \\
\text { Yes }\end{array}$ & $\begin{array}{l}\mathrm{n}=258 \\
90(35) \\
168(65)\end{array}$ & $\begin{array}{l}\mathrm{n}=289 \\
139(48.1) \\
150(519)\end{array}$ & 9.78 & $0.002^{*}$ \\
\hline
\end{tabular}

*Significant

In both rural and urban areas, increasing maternal significant association in the urban area alone. (Table education increased the use of growth chart with a 3)

Table 3: Association between education and use of growth chart

\begin{tabular}{|c|c|c|c|c|c|c|}
\hline \multirow[t]{3}{*}{ Variable } & \multicolumn{6}{|c|}{ Utilization of growth chart $(\%)$} \\
\hline & \multicolumn{3}{|c|}{ Rural $(\mathrm{n}=258)$} & \multicolumn{2}{|c|}{ Urban $(n=289)$} & \multirow[b]{2}{*}{ Total } \\
\hline & Yes & No & Total & Yes & No & \\
\hline \multicolumn{7}{|l|}{ Education } \\
\hline No formal & $5(23.8)$ & $16(76.2)$ & 21 & $3(25.0)$ & $9(75.0)$ & 12 \\
\hline Primary & $18(26.5)$ & $50(73.5)$ & 68 & $15(33.3)$ & $30(66.7)$ & 45 \\
\hline Secondary & $34(28.6)$ & $85(71.4)$ & 119 & $87(51.5)$ & $82(48.5)$ & 169 \\
\hline \multirow[t]{2}{*}{ Post secondary } & $21(42.0)$ & $29(58.0)$ & 50 & $34(54.0)$ & $29(46.0)$ & 63 \\
\hline & $\chi^{2}=4.31$ & \multicolumn{2}{|c|}{$\mathrm{p}=0.230$} & $\chi^{2}=8.14$ & \multicolumn{2}{|c|}{$\mathrm{p}=0.043 *$} \\
\hline
\end{tabular}

*Significant

Among rural women, utilization of growth chart was significantly lowest among those with only one child while it was highest among the same group of urban women. In the rural area; using women with 1 child as a reference category, those with 2 children are 3 times more likely to use the growth chart than their counterparts with only 1 child. (Table 5)

\section{Knowledge about immunization}

The discussants in both rural and urban areas described immunizations as injections given to babies and children to prevent diseases. There were however some misconceptions. "Immunization is given when malaria wants to set in. If a child receives the injection, the malaria will no longer manifest. Also even if the malaria has occurred, immunization will make it not to be too much." (25 years, rural resident) An urban resident described immunization as "Vaccines given to children to prevent them from having diseases that could cost them their lives in the first few years of life". (37 years, urban resident) "Immunization is an antibiotic that the child takes during birth because it takes care of the child up to one year and it helps the child to grow well. It also prevents deadly diseases." (25 years, urban resident)

\section{Treatment-seeking sources and determinants}

Both groups of women had multiple treatment sources for their children but more in the urban area. When they utilized health facilities, they preferred government hospitals for several reasons such as availability of specialists, appropriate investigations and diagnosis before treatment. The private hospitals are more expensive but have short waiting time. They were also reported to 'over-treat' sometimes with injections.

For urban women, the first line of action is usually to treat the children at home with drugs bought from the chemist shop or from drug peddlers/vendors or with 'agbo' (herbal concoction) before taking them to the hospital. Some women consult auxiliary nurses who live close to them. 
Table 5: Association between number of children, education and use of growth chart

\begin{tabular}{|c|c|c|c|c|c|c|c|c|}
\hline \multirow[t]{3}{*}{ Variable } & \multicolumn{8}{|c|}{ Utilization of growth chart $(\%)$} \\
\hline & \multicolumn{3}{|c|}{ Rural $(n=300)$} & \multicolumn{5}{|c|}{ Urban $(\mathrm{n}=300)$} \\
\hline & Yes & No & Total & OR $(95 \% \mathrm{CI})$ & Yes & No & Total & OR $(95 \% \mathrm{CI})$ \\
\hline \multicolumn{9}{|l|}{ Children } \\
\hline 1 & $6(16.2)$ & $31(83.8)$ & 37 & 1 & $26(61.9)$ & $16(38.1)$ & 42 & 1 \\
\hline 2 & $30(39.5)$ & $46(6.5)$ & 76 & $3.37 *(1.16-$ & $56(50.9)$ & $54(49.1)$ & 110 & $0.64(0.29-1.40)$ \\
\hline 3 & $10(20)$ & $40(80)$ & 50 & $10.26)(0.38-4.55)$ & $30(41.7)$ & $42(58.8)$ & 72 & $0.44(0.19-1.03)$ \\
\hline 4 & $18(33.3)$ & $36(66.7)$ & 54 & $2.58(0.83-8.38)$ & $23(44.2)$ & $29(55.8)$ & 52 & $0.49(0.20-1.21)$ \\
\hline \multirow{2}{*}{$\geq 5$} & $14(34.1)$ & $27(65.9)$ & 41 & $2.68(0.81-9.18)$ & $4(30.8)$ & $9(69.2)$ & 13 & $0.27(0.06-1.21)$ \\
\hline & \multicolumn{4}{|c|}{$\chi^{2}=9.54, \mathrm{df}=4, \mathrm{p}=0.049 *$} & \multicolumn{4}{|c|}{$\chi^{2}=6.62, \mathrm{df}=4, \mathrm{p}=0.157$} \\
\hline \multicolumn{9}{|l|}{ Education } \\
\hline No formal & $5(23.8)$ & $16(76.2)$ & 21 & 1 & $3(25.0)$ & $9(75.0)$ & 12 & 1 \\
\hline Primary & $18(26.5)$ & $50(73.5)$ & 68 & $1.15(0.33-4.22)$ & $15(33.3)$ & $30(66.7)$ & 45 & $1.50(0.30-8.26)$ \\
\hline \multirow{3}{*}{$\begin{array}{l}\text { Secondary } \\
\text { Post } \\
\text { secondary }\end{array}$} & $34(28.6)$ & $85(71.4)$ & 119 & $1.28(0.40-4.37)$ & $87(51.5)$ & $82(48.5)$ & 169 & $3.18(0.75-15.42)$ \\
\hline & $21(42.0)$ & $29(58.0)$ & 50 & $2.32(0.65-8.63)$ & $34(54.0)$ & $29(46.0)$ & 63 & $3.52(0.76-18.28)$ \\
\hline & \multicolumn{4}{|c|}{$\chi^{2}=4.31, \mathrm{df}=3, \mathrm{p}=0.230$} & \multicolumn{4}{|c|}{$\chi^{2} 8.14, \mathrm{df}=3, \mathrm{p}=0.043^{*}$} \\
\hline
\end{tabular}

*Significant

"Most Yoruba women give 'agbo' first. When they can no longer control the sickness, they then rush to the hospital." (27 years, urban resident) In the urban area, cost, time, perceived severity of illness and type of ailment also determine where care is sought. "They treat the child at bome first because of lack of money to go to the hospital. If the child does not improve, they borrow money, and when they have borrowed enough money, they then go to the hospital." (28 years, urban resident) "When the child is sick, the mother goes to the chemist or pharmacy shop and when she perceives the illness as serious, she goes to the hospital." (32 years, urban resident)

"They prefer to do self medication with herbal concoctions because they believe that it works faster than drugs. There are a lot of fake drugs around so instead of them taking those drugs, they prefer taking 'agbo' first. Some others prefer going to the chemist to buy drugs and treat their children. If they see that the drug is not working, they then take them to the hospital and sometimes, it is already late and the child may die." (26 years, urban resident)

The traditional birth attendants (TBAs) attend to them quickly and they are cheaper because they will give the child medication which is commensurate with the amount of money presented by the mother. In addition, the mother trusts that whatever the TBA gives them will be effective. The TBAs are also believed to specialize in peculiar ailments, "Some ailments like 'oka' and 'iru inu' (eating of hair in the womb by babies) are treated only by the TBAs. They have what they give to the children and they will pass out the hair. They also have special concoctions for 'oka" (32 years, urban resident)

Generally, there is a preference for orthodox care in the rural area. Rural women take their sick children to General Hospital because there, they carry out tests for accurate diagnosis and treatment of the child. "Most women go to General Hospital. They will take the child and diagnose the problem, but if it is the TBA, they do not have anything to use and test the baby. In the hospital, they will carry out tests to know the type of sickness the child has." (30 years, rural resident)

The type or peculiarity of illness can also determine where care is sought. "Women take the children to hospital when they are sick. There are some diseases that 'Alagbo' (ie TBA) cannot cure. Also there are some sicknesses that cannot be cured in the hospital which the TBA can cure like 'iru inu'. The TBAs also do not give injections unlike in the hospital." (26 years, rural resident) 
Table 4: Respondents' previous history of child death and cause of death

\begin{tabular}{lllll}
\hline Variable & $\begin{array}{l}\text { Rural } \\
\text { Freq( } \%)\end{array}$ & $\begin{array}{l}\text { Urban } \\
\text { Freq }(\%)\end{array}$ & $\chi^{2}$ & p \\
Previous history of child death & & & & \\
Yes & $64(21.3)$ & $73(24.3)$ & 0.77 & 0.381 \\
No & $236(78.7)$ & $227(75.6)$ & & \\
Total & $300(100)$ & $300(100)$ & & \\
\hline Cause of death & $\mathrm{n}=64$ & $\mathrm{n}=73$ & & \\
Illness & $37(57.8)$ & $52(71.2)$ & 5.36 & 0.147 \\
Trauma & $3(4.7)$ & $1(1.4)$ & & \\
Spiritual attack & $3(4.7)$ & $6(8.2)$ & & \\
Don't know & $21(32.8)$ & $14(19.1)$ & & \\
\hline
\end{tabular}

\section{Discussion}

The high awareness of immunization is comparable to findings in a rural community based study in Edo State, Nigeria $(99.9 \%),{ }^{26} 99.8 \%$ in Kinshasa, $\mathrm{DRC}^{10}$ but higher than the 96\% reported in Ethiopia, ${ }^{27}$ and $93.8 \%$ reported by a facility based study in urban Lagos. ${ }^{28}$ Our respondents had poor knowledge of VPDs as a majority of them were mentioned by less than half of the mothers in both rural and urban areas. Rural Ghanaian mothers also had poor knowledge as only $36.7 \%$ of them mentioned Poliomyelitis and Measles of all the diseases covered by EPI. Only 3.3\% of mothers could mention all the EPI diseases. ${ }^{11}$ Similarly in Ethiopia, $77 \%$ of mothers mentioned less than 3 VPDs. ${ }^{27}$

Knowledge that tuberculosis and meningitis are VPDs is low in both groups. This low knowledge of TB as a VPD is likely to impact negatively on its prevention and control in children. It is rather disappointing that all the mothers did not mention poliomyelitis after numerous national and state immunization days to eradicate the disease. Among educated nursing mothers in urban Lagos, similar proportion $(78.57 \%)$ knew poliomyelitis as a VPD while only $5.7 \%$ identified tetanus. ${ }^{29}$ Immunization misconceptions have also been identified in another study in $\operatorname{Lagos}^{28}$ and indicate that mothers may still have poor understanding of the concept of immunization especially for non-VPDs like malaria which have other control measures.

The higher utilization of nutritional counselling services by rural women maybe an indication of higher prevalence of under nutrition among their children as reported by other authors. ${ }^{30}$ Introduction of multiple available opportunities, trained TBAs and home visits could further increase access; an intervention which was effective in improving feeding practices in toddlers in rural India. ${ }^{31}$
Automated growth charts used within Electronic health record (EHR) systems are operational in developed countries. ${ }^{32}$ In developing countries, the measurements are recorded manually in the growth chart. In Riyadh, Saudi Arabia and Baboko, a semi-urban community in Ilorin, Kwara State, Nigeria, overall awareness of growth charts was low and was influenced by maternal age, education, parity and number of living children. ${ }^{24,13}$ In the latter location, there was high utilization among those who had it. Among our respondents, the use of growth chart was significantly higher in the urban than rural area. This may be due to the lower rates of use of immunization and growth monitoring services by the rural women. Most rural health centres use small individual notebooks to record children's weights instead of the standard growth and health record charts supplied by the government (personal communication with a rural nurse) Rural Indian mothers were also reported not to retain and use child health cards. ${ }^{33}$ The importance of maternal education in child healthcare was also highlighted in the use of growth chart.

The higher use of preventive healthcare among urban mothers maybe a reflection of their higher educational status and their proximity to such facilities. In rural Burkina Faso and Nigeria, poor health seeking behaviour was reported among mothers. ${ }^{18,19}$ They practised more of home treatment while the use of orthodox care for childhood illnesses was low. Illness severity, ${ }^{18,19}$ maternal education, income, child gender and number of symptoms predicted care-seeking behaviour. ${ }^{19}$

Presence of traditional healers, who would treat a child based on the financial capacity of its parents and sometimes using promissory, or alternative (trade by barter) mechanisms of payment sometimes drive the mothers to use the home treatments, seeking formal care only when these are seen to fail, or the severity of 
the illness is perceived to be worsening. In rural Mali, mothers have an average of 4 treatment steps including traditional and modern sources for their febrile children. There is a preference for modern treatment though with a lot of failures but they usually start with home treatment. Cost was a major barrier to seeking treatment in the hospital. ${ }^{34}$

In our study (FGDs), cost was considered an issue among the urban poor. They may borrow money to access formal healthcare thus exposing access gaps with their rural counterparts. ${ }^{35,36}$ Urban Ethiopian women were significantly more likely to take their sick children to the health facility. For both groups of women, cost was the most common reason for failing to do so, followed by distance to the health facility (HF) and illness not perceived as serious. ${ }^{37}$ In poorresource settings, appropriate treatment is not even guaranteed in the health facilities ${ }^{18,20,34}$ and mothers will still consult neighbouring unqualified healthcare providers ${ }^{38}$ herbalists and diviners ${ }^{20}$ after visiting the HFs. As reported by our urban discussants, fear of fake and substandard drugs drives some mothers to patronize traditional providers whom they consider more trustworthy. This is evidence of the weak health system operational in most developing countries.

Perceived severity of illness is another determinant of treatment-seeking pattern. Among urban mothers interviewed in Enugu, southeast Nigeria, a majority gave medications at home and only about 1 in 10 of them took the child straight to the health facility. Many of them felt that the child should be taken to the hospital with worsening symptoms, needs specialist attention or alternative treatment failure. ${ }^{39}$

Rural disadvantage in child mortality as has been documented, ${ }^{40}$ was not observed in our study. The high child death rate (mostly due to illness) recorded among both study groups maybe a reflection of the demerits of poor health-seeking behaviour and multiple treatmentsources for childhood illnesses. Factors that may have contributed to this finding were not sought in this study but the growing health risk of urban poverty might explain our findings especially in a country where outof-pocket health expenses are high. Children growing up in poor urban settings face significant health risks, ${ }^{41}$ and in some cases, these risks exceed those prevalent in rural areas. ${ }^{35,36}$

\section{Conclusions \& Recommendations}

Mothers in both rural and urban areas had poor knowledge of VPDs with significantly lower knowledge of tuberculosis among rural women. Both groups of women also had multiple treatment sources for sick children (more in the urban area). Our weak health systems should be strengthened by measures such as increased use of growth charts, elimination of fake and sub-standard medicines and possible adoption of CCM of common childhood illnesses to improve health seeking behaviour among both rural and urban mothers and reduce child mortality.

\section{Limitations}

There is a possibility of recall bias and to minimize this, the index child for questioning was the youngest of the under-fives if there were more than one.

The findings may not represent the country since it was carried out in only one State.

\section{Ethics}

Ethical approval was obtained from the Health Research and Ethics Committee of the Lagos University Teaching Hospital. Written informed consent was obtained from the respondents prior to interview.

\section{References}

1. World Health Organization (WHO): Immunization, vaccines and biologicals. 10 facts on immunization. Available at http://www.who.int/features/factfiles/ immunization/facts/en/index.html. Accessed 4th December, 2012

2. NPHCDA. National Immunization Policy 2009. Available at http://www.thephss.org/ppep/resource/ National_Immunization_Policy_with_frwd_and_acknwldg.pdf. Accessed 29th December 2012.

3. World Health Organization: Weekly Epidemiological Record. No. 46, 2011, 86, 509-520. Available at www. who.int/immunization/3_GlobalcoverageMMWR. Accessed $29^{\text {th }}$ December 2012.

4. WHO, UNICEF, World Bank. State of the world's vaccines and immunization. $3^{\text {rd }} \mathrm{ed}$. Geneva, World Health Organization, 2009. ISBN $97892 \quad 4 \quad 156386$ 4. http://whqlibdoc.who.int/ publications/2009/9789241563864_eng.pdf

5. National Population Commission (NPC) [Nigeria] and ICF Macro. 2009. Nigeria Demographic and Health Survey 2008. Abuja, Nigeria: National Populaton Commission and ICF Macro.

6. Torun SD, Bakirci N. Vaccination coverage and reasons for non-vaccination in a district of Istanbul. BMC Public Health 2006;6:125.

7. Mojoyinola JK, Olaleye BA. Physical and psychological factors influencing maternal non-compliance with immunization schedule. Continental J. Nursing Science 
2012;4(2):37-51.

8. Mapatano MA, Kayembe K, Piripiri L, Nyandwe K. Immunization-related knowledge, attitudes and practices of mothers in Kinshasa, Democratic Republic of Congo. SA Fam Pract 2008;50(2):61.

9. Anand S, Bärnighausen T: Health workers and vaccination coverage in developing countries: an econometric analysis. Lancet 2007;369:1277-85.

10. Abdulraheem IS, Onajole AT, Jimoh AA, Oladipo AR. Reasons for incomplete vaccinations and factors for missed opportunities among rural Nigerian children. J. Public Health Epidemiol 2011;3(4):194-203

11. Singh B, Singh A, Singh N. Determinants of Immunization in Bosomtwe District of Ashanti Ghana. European Journal of Scientific Research. ISSN 1450216X Vol.77 No.1 (2012), pp.77-94

12. Ben-Joseph EP, Dowshen SA, Izenberg N. Public understanding of growth charts: A review of literature. Patient Educ Couns 2007;65(3):288-295.

13. Fabgule DO, Olaosebikan A, Parakoyi DB. Community awareness and utilization of growth chart in a semi-urban Nigerian Communiy. East Afr Med J. 1990;67(2):69-74.

14. Testa J, Sinnaeve O, Ibrahim Y, Ayivi B. Evaluation of the quality of screening and management of infant malnutrition in Cotonou, Benin. Med Trop (Mars). 2008;68(1):45-50.

15. Terra de Souza AC, Peterson KE, Andrade FMO, Gardner J, Ascherio A. Circumstances of post-neonatal death in Ceara, Northeast Brazil. Mothers health careseeking behaviors during infants_fatal illness. Soc Sci Med 2000;51(11):1675-1693.

16. Victora C, Jennifer B, Olivier F, Roeland M. Reducing deaths from diarrhea through oral rehydration therapy. Bull. WHO, 2000;1(78):10.

17. Olaniyan O, Sunkanmi OA. Demand for child healthcare in Nigeria. Glob J Health Sci. 2012;4(6):12940. doi: 10.5539/gjhs.v4n6p129.

18. Wilson SE, Ouédraogo CT, Prince L, Ouédraogo A, Hess SY, Rouamba $\mathrm{N}$ et al. Caregiver recognition of childhood diarrhea, care seeking behaviors and home treatment practices in rural Burkina Faso: a crosssectional survey. PLoS One. 2012;7(3):e33273. doi: 10.1371

19. Abdulraheem IS, Parakoyi DB. Factors affecting mothers' healthcare seeking behaviour for childhood illnesses in a rural Nigerian setting. Early Child Dev. Care 2009;179(5):671-83.

20. Sharkey AB, Chopra M, Jackson D, Winch PJ, Minkovitz CS. Pathways of care-seeking during fatal infant illnesses in under-resourced South African settings.
Trans R Soc Trop Med Hyg. 2012;106(2):110-6. doi: 10.1016/j.trstmh

21. Malhotra C, Malhotra R, Ostbye T, Subramanian SV. Maternal Autonomy and Child Health Care Utilization in India: Results From the National Family Health Survey. Asia Pac J Public Health. 2012 May 31. [Epub ahead of print]

22. Littrell M, Moukam LV, Libite R, Youmba JC, Baugh G. Narrowing the treatment gap with equitable access: mid-term outcomes of a community case management program in Cameroon. Health Policy Plan. 2012 Nov 11. [Epub ahead of print]

23. Kisia J, Nelima F, Otieno DO, Kiilu K, Emmanuel W, Sohani S, Siekmans K, Nyandigisi A, Akhwale W. Factors associated with utilization of community health workers in improving access to malaria treatment among children in Kenya. Malar J. 2012 30;11:248. doi: 10.1186/1475-2875-11-248.

24. Al-Nahedh N, Bamgboye EA. Influence of mothers' characteristics on their perceptions and use of the growth chart. East Mediterr Health J. 2003;9(5-6):97480.

25. Mbonye AK. Prevalence of Childhood Illnesses and Care-Seeking Practices in Rural Uganda. ScientificWorldJournal 2003;3:721-730. doi:10.1100/tsw.2003.52

26. Odusanya OO, Alufohai EF, Meurice FP, Ahonkai VI: Determinants of vaccination coverage in rural Nigeria. BMC Public Health 2008;8:381.

27. Etana B, Deressa W: Factors associated with complete immunization coverage in children aged 12-23 months in Ambo Woreda, Central Ethiopia. BMC Public Health 2012;12:566.

28. Awodele O, Oreagba IA, Akinyede A, Awodele DF, Dolapo DC. The knowledge and attitude towards childhood immunization among mothers attending antenatal clinic in Lagos University Teaching Hospital Nigeria. Tanzan. J. Health Res. 2010;12(3):172-177.

29. Iorngurum MT, Ariyo OT: Knowledge of vaccine preventable diseases among nursing mothers attending paediatric clinic in Lagos University Teaching Hospital: Arch Dis Child 2010;95(6) doi: 10.1136/ adc.2010.190322.19

30. Oninla SO, Owa JA, Onayade AA, Taiwo O. Comparative Study of Nutritional Status of Urban and Rural Nigerian School Children. J Trop Pediatr 2007;53(1):3943. doi: 10.1093/tropej/fml051

31. Bhandari N, Mazumder S, Bahl R, Martins J, Black RE, Bhan MK et al. Use of multiple opportunities for improving feeding practices in under-twos within child health programmes. Health Policy Plan. 2005;20(5):328336. 
32. Rosenbloom ST, Qi X, Riddle WR, Russell WE, DonLevy SC, Giuse D et al. Implementing pediatric growth charts into an electronic health record system. J Am Med Inform Assoc. 2006;13(3):302-8.

33. Pahari DP, Bastola SP, Paudel R. Factors affecting retention of child health card in a rural area. J Nepal Health Res Counc. 2011;9(2):154-158.

34. Ellis AA, Traore S, Doumbia S, Dalglish SL, Winch PJ. Treatment actions and treatment failure: case studies in the response to severe childhood febrile illness in Mali. BMC Public Health. 2012;12:946. doi: 10.1186/14712458-12-946.

35. Montgomery MR, Urban Poverty and Health in Developing Countries: Popul Bull 2009; 64(2):6.

36. Bitran J, Keeping Health in an Urban Environment: Public Health Challenges for the Urban Poor; in The Urban poor in Latin America, Edited by M.Fay. The World Bank. Washington. D.C., 2005, 179-194.

37. Assefa T, Belachew T, Tegegu A, Deribew A. Mothers' health care seeking behaviour for childhood illness in Derra District, Northshoa Zone, Oromia Regional State, Ethiopia. Ethiop J Health Sci 2008;18(3):87-94. 38. Shah MS, Ahmad A, Khalique N, Afzal S, Ansari MA, Khan Z. Home-based management of acute diarrhoeal disease in an urban slum of Aligarh, India. J Infect Dev Ctries. 2012;6(2):137-42.

39. Ezeoke UE, Nwobi EA, Ekwueme OC, Tagbo B, Aronu E, Uwaezuoke S: Pattern of Health Seeking behaviour of mothers for common childhood illness in Enugu metropolis, South East Zone, Nigeria: Nigerian J Clin Pract 2010;13:37-40.

40. Van de Poel E, O'Donnell O, Van Doorslaer E: What explains the rural-urban gap in infant mortality: household or community characteristics? Demography 2009; 46(4); 827-50.

41. UNICEF. The State of the Worlds' Children 2012: Children in an urban world; UNICEF February 2012, http://www.unicef.org/sowc2012/pdfs/SOWC\%20 2012-Main\%20Report_EN_13Mar2012.pdf accessed on $19^{\text {th }}$ August, 2012. 